\title{
Japan puts down the welcome mat for foreign researchers
}

Tokyo

UNDER fire for failing to make its contribution to the world store of basic research knowledge (but see below), Japan is struggling to remedy the situation. The issue has come to the fore in negotiations over the US-Japan Science and Technology Agreement (Nature 329, 662; 1987).

The impression of a one-way trade in researchers between Japan and the United States is confirmed by a Nomura Research Institute survey carried out in 1983 at the request of the Science and Technology Agency and by recent figures from the Japanese immigration department. Some 16,000 Japanese scientists and engineers visit the United States each year while only about 2,000 travel in the other direction.

The Ministry of Education, Science and Culture is trying to change the situation. It has applied for $¥ 373$ million (\$2.7 million) in fiscal year 1988 to invite 100 postdoctoral fellows for a year from the United States and Europe, in addition to the 30 already invited from Britain, France and West Germany. The Science and Technology Agency has also applied for extra money for foreigners: $¥ 600 \mathrm{mil}$ lion (\$4.4 million) in fiscal 1988. Also, the Ministry of International Trade and Industry (MITI) is considering accepting US engineering postdoctoral fellows. As a result, Alexander DeAngelis of the US National Science Foundation office in Tokyo, says there will be a "substantial increase" in the number of American scientists visiting Japan in the next year.

But will postdoctoral researchers want to come? The ten fellowships available to British scientists each year are often undersubscribed and West Germany barely fills its quota. This unwillingness probably stems from the lack of employment opportunities for foreign academics, concern over the language problems and fear of isolation from the Western research community. Japan's laws were rewritten in 1983 to allow appointment of foreigners in faculty positions. But so far only 61 have been appointed in Japan's 95 national universities, and only a handful enjoy full tenure like their Japanese colleagues. Many of the appointees are Chinese, Koreans and Japanese-Americans.

Some new efforts are being made to employ foreign researchers at Tokyo University. The university has introduced a scheme that allows private companies to endow funds for guest and assistant professorships for periods of one to five years. Four companies (NEC, Nippon Telegraph and Telephone, CSK - a computer manufacturer - and Shin Nippon Steel) have endowed four posts.
The situation in government laboratories is even worse. There is only one foreigner on the staff of a government institute. When Dr Thomas Barnes of Britain joined MITI's Electrotechnical Laboratory in Tsukuba in September, it made the national news.

But it is the imbalance in the private sector that most concerns the United States. A large proportion of the researchers visiting the United States are from private companies. Many of the superconductor researchers at NEC and Toshiba were trained in US laboratories, as have many researchers in the Japanese biotechnology industry.

At the heart of the problem may lie structural differences between the US and Japanese research systems. The bulk of Japanese research is funded by the private sector and is largely applications-orientated. Much of Japan's technology is the envy of the world and several foreign companies, such as Du Pont and ICI, have recently set up laboratories here to tap Japan's excellence. On the other hand, Japan's comparative weakness in basic research means that it has less to offer researchers at its universities and institutes.

Even gaining access to information on Japanese science and technology is not easy for US researchers. Japanese researchers can plug their computers into US databases: 8,000 Japanese users are already linked to the US DIALOG database. But Japanese databases and computer networks are not so advanced and much of the information is in Japanese.

David Swinbanks \& Harry Glicken

\section{Japan's international standing improved by paper boom?}

\section{Tokyo}

Is Japan's performance in basic research really as bad as critics think? A new report from the Ministry of Education, Science and Culture presents a more positive picture: in terms of number of publications, Japan now ranks second only to the United States in many fields of science.

The ministry analysed the country of origin of publications listed in four databases, INSPEC (published by Britain's Institute of Electrical Engineers), EMBASE (The Netherlands' Excerpta Medica), COMPENDEX (US Engineering Information) and Chemical Abstracts (US). The survey shows a remarkable increase in the number of Japanese publications over the past decade. In genetics, for example, contributions have shot up fourfold, and in 1985 surpassed those of
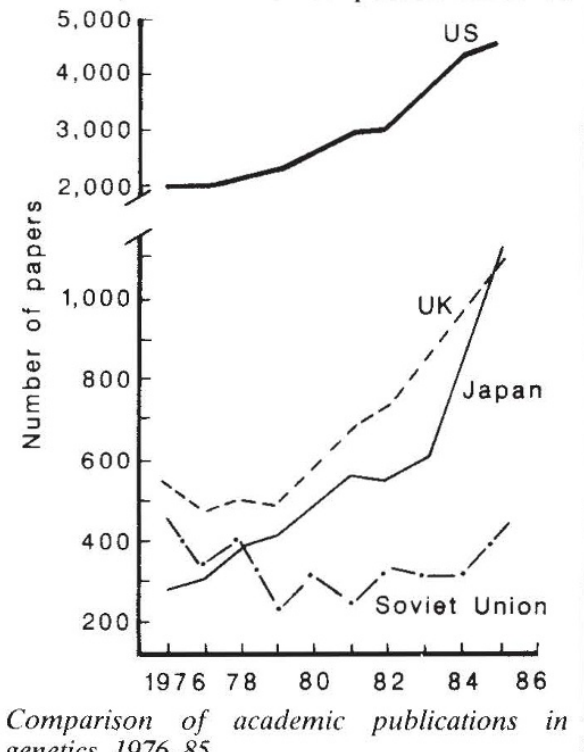

Comparison of academic publications in genetics, $1976-85$.
Britain, placing Japan second only to the United States. Japan also ranked second in 12 fields, including cancer research, electronics and electrical engineering and agricultural chemistry, and third in the other 11 fields analysed.

On release of the results last week. Japanese newspapers boldly declared that Japan is now number two in producing publications in leading journals, such as Nature and Science. And Hiroshi Ueki of the ministry's science and international affairs bureau says the survey shows that the quality of Japanese science is close to the best international standards.

But the ministry's survey drew data from more than 10,000 journals published in English, and the quality of many is open to question. For example, The Japanese Journal of Applied Physics announced in March that it would abandon peer review of papers on high-temperature superconductors because of a flood of contributions. And for many other journals, refereeing is more a formality than a strict assessment.

A different picture comes from a survey carried out by the Science and Technology Agency in the summer. By analysing the frequency of citations of Japanese papers, it ranked Japan fifth in basic science, well behind the United States, West Germany, France and Britain.

But can such measures be used to assess the standard of Japanese science? Many Japanese researchers complain that their work often goes uncited by Western researchers. It is well known that scientists tend to refer to the work of people they know, and as long as Japan remains comparatively isolated, its research will be underrated.
David Swinbanks 